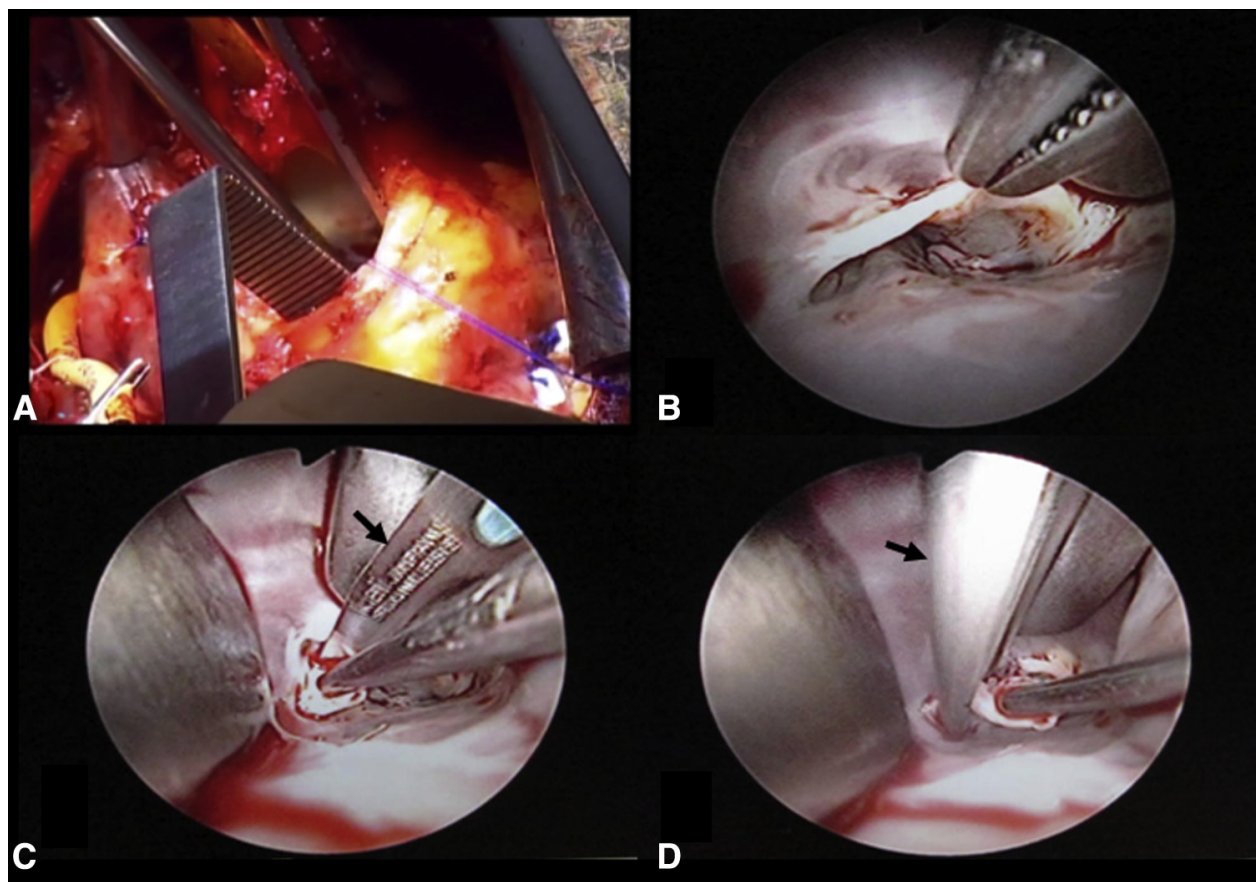

FIGURE 2. Intraoperative images. A, Exposure is obtained with angled retractors. B, Intraoperative endoscopy showing the subaortic membrane. C, An endoscopic image showing resection of the subaortic membrane with an angled scalpel (black arrow). D, Resection of the subaortic membrane with an angled scissors (black arrow).

with such devices. We hope for further development of similar useful devices in cardiovascular surgery.

\section{References}

1. Morrow AG, Brockenbrough EC. Surgical treatment of idiopathic hypertrophic subaortic stenosis: technic and hemodynamic results of subaortic ventriculomyotomy. Ann Surg. 1961;154:181-9.
2. Douville EC, Sade RM, Crawford FA Jr, Wiles HB. Subvalvular aortic stenosis: timing of operation. Ann Thorac Surg. 1990;50:29-33; discussion 33-4.

3. Ashraf H, Cotroneo J, Dhar N, Gingell R, Roland M, Pieroni D, et al. Long-term results after excision of fixed subaortic stenosis. J Thorac Cardiovasc Surg. 1985; 90:864-71

4. Hirata Y, Chen JM, Quaegebeur JM, Mosca RS. The role of enucleation with or without septal myectomy for discrete subaortic stenosis. J Thorac Cardiovasc Surg. 2009;137:1168-72.

\title{
Repair of anomalous aortic origin of coronary arteries with combined unroofing and unflooring technique
}

\author{
Hagi Dekel, MD, Edward J. Hickey, MD, Jack Wallen, MD, PhD, and Christopher A. Caldarone, MD, \\ Toronto, Ontario, Canada
}

\footnotetext{
From the Division of Cardiovascular Surgery, Hospital for Sick Children, Labatt Family Heart Center and University of Toronto, Toronto, Ontario, Canada.

Disclosures: Authors have nothing to disclose with regard to commercial support.

Received for publication Dec 1, 2014; revisions received April 17, 2015; accepted for publication May 3, 2015; available ahead of print June 4, 2015.

Address for reprints: Christopher A. Caldarone, MD, The Hospital for Sick Children, 555 University Ave, Suite 1525, Toronto, ON M5G 1X8, Canada (E-mail: chris caldarone@sickkids.ca).

J Thorac Cardiovasc Surg 2015;150:422-4

$0022-5223 / \$ 36.00$

Copyright (c) 2015 by The American Association for Thoracic Surgery

http://dx.doi.org/10.1016/j.jtcvs.2015.05.013
}

See related commentary on pages 425-6.

Anomalous aortic origin of a coronary artery (AAOCA) is a congenital anomaly in which a major coronary artery arises from the atypical sinus of Valsalva and commonly courses within the aortic wall (intramural) or between the great arteries before reaching its normal epicardial distribution. AAOCA predisposes affected persons toward hemodynamic collapse during or shortly after strenuous exercise. 
TABLE 1. Patient data

\begin{tabular}{llccccccc}
\hline & & \multicolumn{9}{c}{ Morphology } & & \multicolumn{2}{c}{ Repair techniques } \\
\cline { 3 - 5 } \cline { 3 - 4 } Patient & Age & Type & Slitlike & Intramural & Interarterial & & Unroofing and unflooring & Reimplantation \\
\hline 1 & $17 \mathrm{y}$ & AAORCA & Yes & Yes & Yes & & Yes & Yes \\
2 & $32 \mathrm{y}$ & AAORCA & Yes & Yes & Yes & & Yes & Yes \\
3 & $49 \mathrm{y}$ & AAORCA & Yes & Yes & No & & Yes & No \\
4 & $7 \mathrm{~d}$ & AAOLCA & Yes & Yes & No & & Yes \\
\hline
\end{tabular}

AAORCA, Anomalous aortic origin of the right coronary artery; AAOLCA, anomalous aortic origin of the left coronary artery.

Patients in whom surgical repair is indicated include those with symptoms (aborted sudden cardiac death, syncope, or chest pain during exercise) and those without symptoms but with documented ischemia during stress tests. ${ }^{1}$ Surgical repair techniques include coronary artery reimplantation, unroofing the intramural segment, pulmonary artery relocation, neo-ostium creation, patch angioplasty, and coronary artery bypass grafting. ${ }^{2}$

We have combined standard unroofing techniques with concomitant "unflooring" techniques to augment the antiaortic side of the coronary artery with a longitudinal patch. If an interarterial course needs to be addressed, a coronary artery reimplantation can also be added. Together, the combination creates a useful tool for the surgeon to consider.

\section{CLINICAL SUMMARY \\ Patients}

Four patients with AAOCA underwent repair with combined unroofing and unflooring with or without reimplantation (Table 1).

\section{Technique}

After establishment of standard cardiopulmonary bypass and cardioplegic arrest, an aortotomy is performed and the origin of the anomalous coronary artery is examined for the shape of the ostium (eg, slitlike or round), the presence of an intramural portion, the relationship of the intramural portion to the aortic valve commissure, and the presence of an interarterial course between the aorta and the main pulmonary artery. We start with the conventional unroofing technique, ${ }^{3}$ which includes excising the common wall between the aorta and the coronary artery, followed by unflooring, making a longitudinal incision in the aortic wall that extends across the coronary ostium on the antiaortic side and up the coronary artery. ${ }^{4}$ Glutaraldehyde-treated autologous pericardium is used to augment the coronary ostium (Figure 1).

If the anomalous coronary artery has an arterial course that is likely to result in compression between the aorta and the pulmonary artery after the combined unroofing and unflooring procedure, then reimplantation is considered. If reimplantation is deemed appropriate, then a
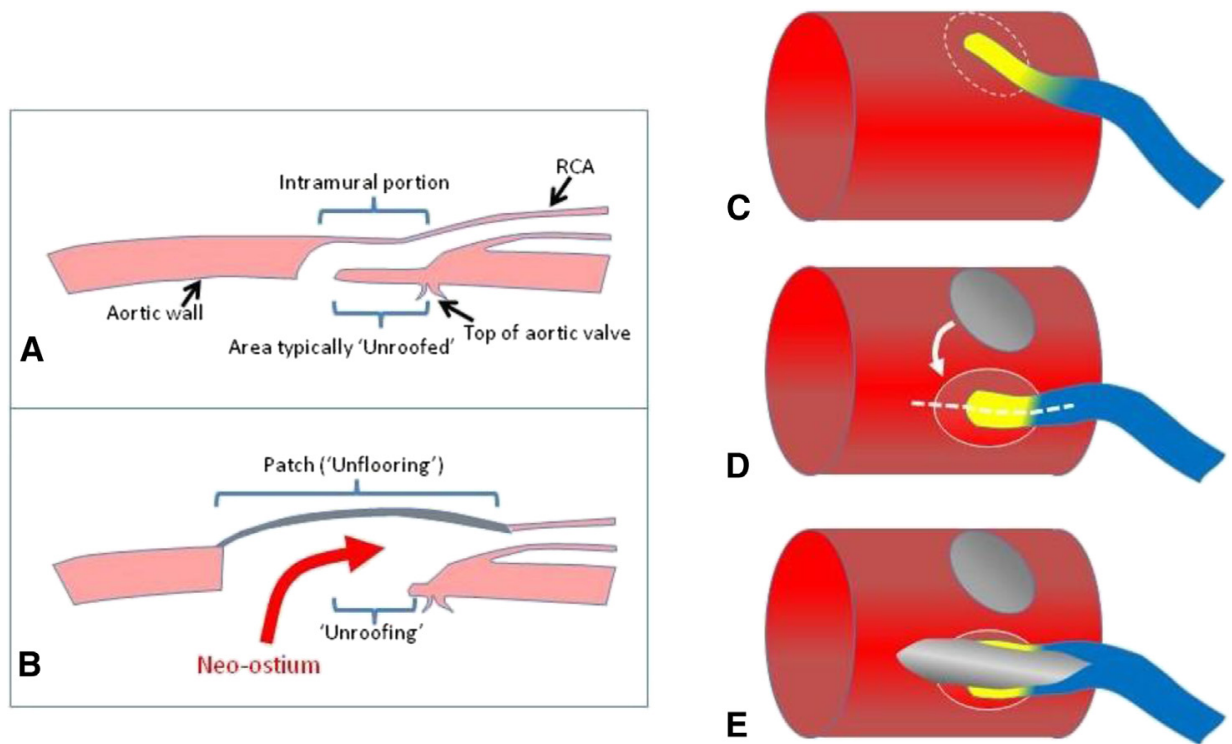

FIGURE 1. A, Schematic cross-section of the aortic wall with anomalous aortic origin of a coronary artery and an intramural segment. B, After combined unroofing and unflooring, the anomalous coronary artery ostium is widely patent. C, For patients requiring reimplantation, a coronary button is created that contains the coronary ostium and the entire unroofed intramural course (dotted line). D, A glutaraldehyde-treated pericardial patch is used to close the site of the coronary button harvest, and the coronary button is then reimplanted in the new optimal location. Before completion of the anastomosis, an incision is in the coronary artery, through the coronary artery button, and then through the corresponding portion of the aortic wall (dotted line). E, A glutaraldehydetreated autologous pericardial patch is used to augment the coronary ostium. $R C A$, Right coronary artery. 
coronary button is mobilized after unroofing. The coronary button contains the coronary ostium and the entire unroofed intramural course. A glutaraldehyde-treated pericardial patch is used to close the site of the coronary button harvest, with the patch kept relatively small to avoid distortion of the sinotubular junction. Occasionally, the top of the aortic valve commissure must be resuspended. When resuspension is required, the top of the commissure can be anchored in the pericardial patch. The coronary button is then fully mobilized along the coronary artery. It is often helpful to identify the optimal location for reimplantation by distending the aorta with cardioplegia and distending the right ventricle by temporarily decreasing venous return in the cardiopulmonary bypass circuit.

Once the site for reimplantation has been identified, an incision in the aorta is created in a manner analogous to an arterial switch procedure. The coronary button is then sutured into place along the base and sides of the coronary button, leaving the top portion of the anastomosis incomplete. A longitudinal counterincision is then made along the coronary artery and extended across the unsewn portion of the coronary button anastomosis and across the adjacent aortic wall. The coronary artery is incised beyond the end of the unroofing. To avoid potential anastomotic difficulties created by ending the patch immediately opposite the end of the unroofing, we generally recommend extending the unflooring incision for a distance equivalent to twice the coronary diameter. It is important, however, to avoid approaching any coronary artery branches.

A glutaraldehyde-treated pericardial patch is used to augment the newly constructed coronary ostium, thereby completing the unflooring portion of the procedure. It is, of course, critically important to avoid stenosis of the coronary artery at the distal end of the pericardial patch. We typically sew the patch over a dilator with interrupted sutures to avoid potential stenosis.

\section{Results}

In all 4 of our patients, intraoperative transesophageal and epicardial echocardiography demonstrated good biventricular function, and the coronary arteries appeared to be widely patent with normal flow patterns.

\section{DISCUSSION}

The surgical objective of AAOCA repair is to create a widely patent coronary artery ostium that is resistant to fluctuations in aortic and pulmonary arterial pressures. We have used a combination of techniques that include combined unroofing and unflooring along with coronary artery reimplantation to address this surgical challenge. Demonstration of the efficacy of this approach, however, will take decades of follow-up.

From a practical perspective, we find the approach useful because we have not been satisfied with simple unroofing procedures. Resection of the common wall between the aorta and the coronary artery is frequently problematic because of the inherent limitation in the ostial enlargement that can be obtained through simple resection. The limits of resection are determined by the need to avoid resecting beyond the common wall and entering the fatty tissue outside the vessel lumen. Once transgressed, the intima must be reapproximated. The limits to enlargement are thus determined by the geometric dimensions of the resectable common wall, and this may not always be sufficient. Furthermore, extravascular resection requires suture repair, which may set the stage for restenosis.

Addition of the unflooring portion of the procedure allows the surgeon to enlarge the neo-ostium to whatever size is required, and because of the larger size, the combined technique may be more resistant to restenosis. The price of this approach, however, is the potential for aneurysm formation and patch dehiscence.

\section{CONCLUSIONS}

The combination of unroofing and unflooring and reimplantation is a useful method to repair AAOCA and create a widely patent coronary artery ostium.

\section{References}

1. Angelini P. Coronary artery anomalies: an entity in search of an identity. Circulation. 2007;115:1296-305.

2. Poynter JA, Bondarenko I, Austin EH, DeCampli WM, Jacobs JP, Ziemer G, et al; Congenital Heart Surgeons' Society AAOCA Working Group. Repair of anomalous aortic origin of a coronary artery in 113 patients: a Congenital Heart Surgeons' Society report. World J Pediatr Congenit Heart Surg. 2014;5:507-14.

3. Frommelt PC, Sheridan DC, Berger S, Frommelt MA, Tweddell JS. Ten-year experience with surgical unroofing of anomalous aortic origin of a coronary artery from the opposite sinus with an interarterial course. J Thorac Cardiovasc Surg. 2011;142:1046-51.

4. Karl TR. Coronary artery from the wrong sinus of Valsalva: a physiologic repair strategy. Oper Tech Thorac Cardiovasc Surg. 2008;13:35-9. 